\title{
Experimental evaluation of heat and moisture transmission characteristics of the working ensemble of hot coal mines using the thermal manikin
}

\author{
Xing Tong*, Weiqi Guo, Kaiqian Kang, Yueping Qin \\ School of Resources \& Safety Engineering, China University of Mining \& Technology, Beijing \\ 100083, China
}

Email: tongxing163email@163.com

\begin{abstract}
In this paper, the thermal transmission capability (thermal insulation) and the moisture transmission characteristic (evaporative resistance) of the working ensemble for Chinese hot coal miners (from Jining Anju coal mine, a typical hot coal mine in China) were measured and analyzed using a thermal sweating manikin ("Newton") in a climatic chamber. It is found that the thermal insulation of the old (used) mining ensemble worn for one year changes slightly from the new one, but the evaporative resistance decreases about $15 \%$; there are notable differences of local thermal insulation and local evaporative resistance of the mining ensemble among different body zones; the thermal insulation and the evaporative resistance of the mining ensemble change slightly under different thermal conditions, but vary significantly under different humid conditions. The measured data of thermal insulation and the evaporative resistance can provide technical and data support for mining ensemble design, and also are valuable data for evaluating thermal strain of workers in hot coal mines.
\end{abstract}

Keywords: Mine Thermal Hazard, Mining Ensemble, Thermal Insulation, Evaporative Resistance, Thermal.

\section{INTRODUCTION}

In recent years, with the increasing mining depths and the improving mining mechanization, heat hazards have been becoming more frequent and serious in underground coal mines in China. In some coal mines with a mining depth beyond $1000 \mathrm{~m}$, the dry bulb temperature at the working face can reach $40{ }^{\circ} \mathrm{C}$ and the relative air humidity is up to $90 \% \sim 100 \%$ [1]. Heat hazards to miners at the working face in underground hot coal mines in China have been therefore becoming more severe these years [2-4].

In underground coal mines, miners are working in a microclimate which consists of air, the working uniform and human body, while the working uniform is the thermalevaporative transmission medium between human body and the microclimate. Thus, the thermal transmission capability (thermal insulation) and the moisture transmission characteristic (evaporative resistance) of the mining uniform are significantly important to keep the thermal balance for coal mine workers. At present, in the study on the evaluation of heat stress in hot coal mines, the thermal insulation (TI) and the evaporative resistance (ER) of the mining uniform are generally empirically given according to other similar clothes [5-9], and the TI and ER of the entire working ensemble (including coats, trousers and leather boots) are still not accurately and objectively acquired. Therefore, the determination and analysis of TI and ER of the working ensemble for hot coal mines in China are necessary and of great importance for the thermal safety and thermal comfort assessment.

Because of the differences between individuals and the difficulty in measuring heat-moisture dissipation of human body accurately, measurement of TI and ER using thermal sweating manikin is currently becoming the internationallypopular approach, especially for the working ensemble or uniform. This measurement technique is objective, accurate and repeatable [10]. In the past decade, many researches employed the thermal manikin to measure and analyze many kinds of clothes, such as Firefighters' protective uniform, anti-static clothing and so on [11-13].

Measurement Technology Northwest developed an advanced thermal sweating manikin named "Newton", which imitates the human body heat condition objectively [14]. This system divides the body model into 20 or 34 individual thermal controlled parts and manikin sweeting skin was made of detachable fabric and hence localized thermal insulation and evaporative resistance can be gauged. "Newton" has been widely used to determine many kinds of working ensembles [15].

In this paper, 20-zone "Newton" was used to evaluate the thermal insulation and the evaporative resistance of two working ensembles for coal miners (from Jining Anju coal mine, a typical hot coal mine in China) in a climatic chamber. Besides the measurement of the thermal insulation and the evaporative resistance of the mining uniform in standard thermal condition, this study further analyzed the effects of 
thermal conditions and humid conditions on the variation of the thermal insulation and the evaporative resistance of the mining ensemble equipped in underground hot coal mines.

\section{METHODOLOGY}

\subsection{Measurement apparatus and test objects}

A 20-zone "Newton" type thermal manikin was used in the measurement. Each zone of "Newton" has independent heating and sensing system which is a thermostatic constant power system. The sweating skin system consists of 20 individual water components which control sweeting pace by valves and external pressure pump which is detached from the manikin body. The working and controlling system of "Newton" is shown in Figure 1, and the 20 individual body zones of Newton are listed in Figure. 2. Thermal and water vapor accommodation of "Newton" is controlled by the ThermDAC software installed in a computer. ThermDAC can control the operating temperature, heat release and volume of perspiration individually and undertake the measurement, manipulation, record and transmission of experimental data simultaneously [14].

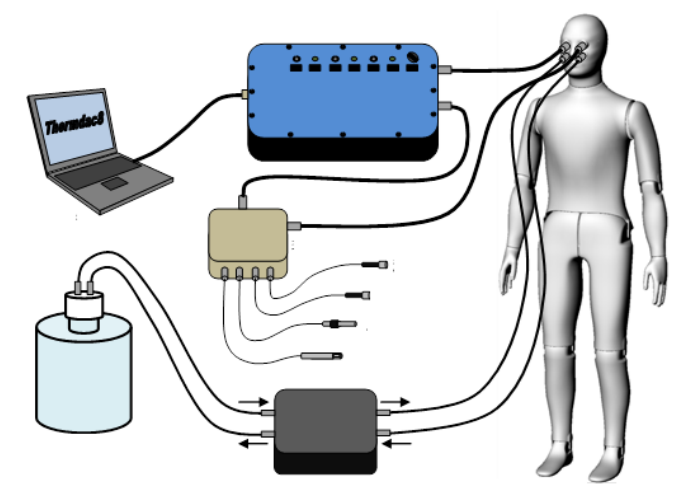

Figure 1. Working and controlling system of "Newton"

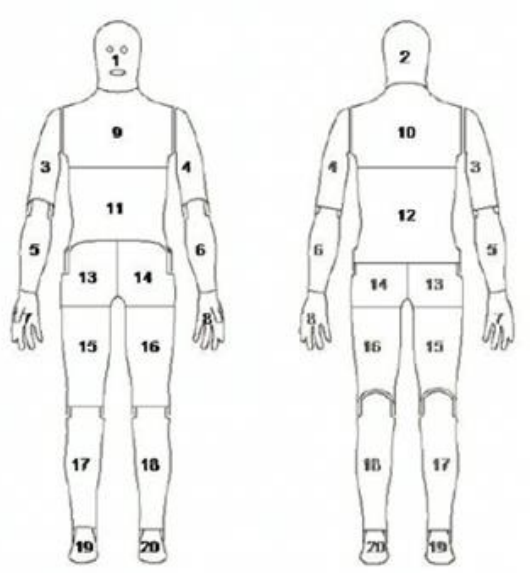

Figure 2. 20 body zones of "Newton"

All tests were conducted in a climatic chamber of $6 \mathrm{~m}$ long, $5 \mathrm{~m}$ wide and $2.7 \mathrm{~m}$ high. The temperature and relative humidity can be controlled at $18 \sim 48^{\circ} \mathrm{C} \pm 0.5^{\circ} \mathrm{C}$ and $30 \sim 90 \% \pm 5 \%$ RH. The climatic chamber is isolated from the outdoor environment so that the heat exchange with external environment would be minimized to the lowest level. There are 10 thermocouples (WZP-PT100, China; accuracy: $\pm 0.1^{\circ} \mathrm{C}$ ) placed in the chamber to detect the experiment temperature and there are several humidity sensors (AM-101, Japan; accuracy: $\pm 3 \%$ ) scattered in the middle of chamber to detect experiment humidity.

Test samples are one new mining ensemble and a 1-yearworn mining ensemble (both collected from Jining Anju coal mine, a typical hot coal mine in China), and both of them include coats, trousers and leather boots. Since the controlling circuit was arranged on the head of the manikin, safety helmet for miners is not available to measure by the thermal manikin, and therefore the thermal insulation and evaporative resistance of safety helmet were not measured in this experiment. The experimental sample and the test setup is shown in Figure. 3 and Figure. 4 shows the snapshot of measurement setup with ThermDAC of "Newton".
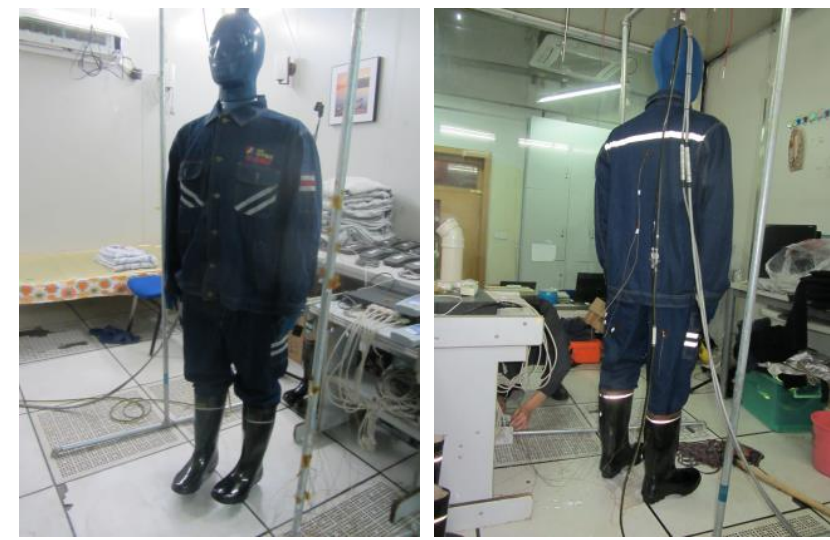

Figure 3. Measurement setup in a climatic chamber with "Newton" manikin

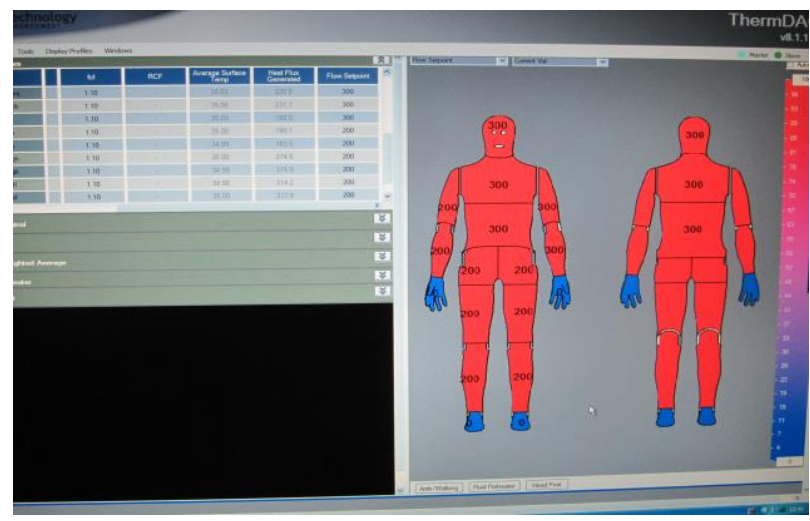

Figure 4. Measurement setup with the ThermDAC of "Newton" manikin

\subsection{Calculation method for thermal insulation and evaporative resistance}

The physical significance of clothing thermal insulation is the reflection of heat flow resistance caused by the temperature gradient, and the value of thermal insulation is the ratio of temperature difference between two surfaces to heat flux which flows per area unit vertically. Formulas of local thermal insulation are given below [16]:

$$
I_{t, i}=\frac{T_{s k, i}-T_{a}}{Q_{t, i}}
$$


$I_{a, i}=\frac{T_{s k, i}-T_{a}}{Q_{a, i}}$

where, $i$ is the zone number of each manikin parts; $I_{t, i}$ is the thermal insulation $\left(\mathrm{m}^{2} \mathrm{~K} / \mathrm{W}\right)$ of the corresponding zone $i$ and it includes the fabric thermal insulation and the air boundary layer thermal insulation; $I_{a, i}$ is the thermal insulation $\left(\mathrm{m}^{2}\right.$ $\mathrm{K} / \mathrm{W}$ ) of boundary air layer of nude manikin and it is also called surface thermal insulation; $Q_{t, i}$ is the heat output $\left(\mathrm{W} / \mathrm{m}^{2}\right)$ of zone $i$ of the dressed manikin and the $Q_{a, i}$ is the heat output $\left(\mathrm{W} / \mathrm{m}^{2}\right)$ of zone $i$ of the naked manikin; $T_{s k, i}$ is the skin temperature $(\mathrm{K})$ of the corresponding manikin zone $i$; $T_{a}$ is the ambient testing temperature $(\mathrm{K})$. Total thermal insulation is calculated in parallel and serial way according to the local thermal insulation of each zone. Serial total thermal insulation and parallel total thermal insulation are calculated as follows [16, 17]:

$$
\begin{aligned}
& I_{t, s}=\sum_{i=1}^{N}\left(I_{t, i} \times a_{i}\right) \\
& I_{t, p}=1 / \sum_{i=1}^{N} \frac{a_{i}}{I_{t, i}}
\end{aligned}
$$

where, $N$ is total number of manikin zones; $a_{i}$ is the ratio of the corresponding zone area to total area. Another commonly used parameter is basic thermal insulation which is the total thermal insulation calculated from skin surface to clothing surface, and it is calculated as follows [16]:

$I_{c l}=I_{t}-I_{a} / f_{c l}$

where, $I_{c l}$ is basic thermal insulation; $I_{t}$ is total thermal insulation; $I_{a}$ is nude thermal insulation; $f_{c l}$ is clothing area factor that is generally given as 1.18 considering the swell of uniform while the uniform was put on.

The local evaporative resistance is calculated based on the following equation $[16,17]$ :

$$
R_{e t, i}=\frac{P_{s k}-P_{a}}{Q_{i}-\left[\left(T_{s k}-T_{a}\right) / I_{t, i}\right]}
$$

where, $R_{e t, i}$ is the local evaporative resistance $\left(\mathrm{Pa} \mathrm{m}^{2} / \mathrm{W}\right), P_{s k}$ is saturation vapor pressure $(\mathrm{Pa})$ corresponding to the skin surface temperature, $P_{a}$ is partial pressure $(\mathrm{Pa})$ of ambient water vapor, $Q_{i}$ is the total heat exchange $\left(\mathrm{W} / \mathrm{m}^{2}\right)$ between the manikin and the ambient environment.

$P_{\mathrm{sk}}=133.3 \times 10^{\left[8.10765-\left(\frac{1750.29}{235+T_{\mathrm{sk}}}\right)\right.}$

$P_{\mathrm{a}}=R H \times 133.3 \times 10^{\left[8.10765-\frac{1750.29}{235+T_{\mathrm{a}}}\right]}$

where, $R H$ is relative humidity in the testing chamber. Total evaporative resistance and basic water vapor resistance calculated in serial and parallel way could be derived from equation (3) (5).

Most types of clothing ensembles have openings, e.g. collars, cuffs, which allow a certain air exchange with the environment. This air exchange can increase, changing the thermal insulation of the clothing when the work is performed This is called the "pumping effect". Also, the wind can enter through the openings, increasing the air exchange of the microclimate air with the external environment. As a result, thermal insulation moisture transfer ability of the clothing can be reduced by the movement of human body or the air velocity. Havenith et al. (2004) proposed a widely used formula to determine the dynamic thermal insulation characteristics of clothing as described in Equation (9) [18]:

$$
I_{t, R}=\operatorname{corr}_{t} \times I_{t}=e^{\left[-0.281 \times\left(v_{a r}-0.15\right)+0.044 \times\left(v_{a r}-0.15\right)^{2}-0.492 v_{w}+0.176 v_{w}{ }^{2}\right]} \times I_{t}
$$

where $I_{t, R}$ is the corrected dynamic thermal insulation taking account for the effects of human movement and relative air velocity, $\operatorname{corr} I_{t}$ is the correction factor, $v_{a r}$ is the relative air velocity between human body and the air, $v_{w}$ is the moving speed of human body. $I_{t}$ is the static thermal resistance.

\section{RESULTS AND DISCUSSIONS}

\subsection{Standard measurement results}

Firstly, the thermal insulation and the evaporative resistance of the mining ensemble were measured under standard procedure and thermal conditions and humid conditions that corresponding to ISO 9920 (Ergonomics of the thermal environment estimation of the thermal insulation and water vapour resistance of a clothing ensemble) [19].

The testing temperature for the thermal insulation of the mining ensemble in the climatic chamber was $25 \pm 0.3^{\circ} \mathrm{C}$ and the relative humidity was $55 \% \pm 3 \%$. Air velocity was less than $0.2 \mathrm{~m} / \mathrm{s}$. We measured the thermal insulation in the conditions in which manikin wore fabric skin only (nude) and wore mining uniform, respectively. In this experiment, we set the surface temperature of "Newton" constantly as $35^{\circ} \mathrm{C}$ and the operation mode of the manikin is non-sweating. Considering the uncertainty in the experiment, every experiment lasted 60 minutes and the terminal temperature and heat flux recorded at one-minute intervals after heat output of each zone was steady for 30 minutes. Furthermore, we conducted every experiment for four times, and selected the best three results and then take the average of these three measure data as the final measurement value. The calculation of thermal insulation was based on 18 body zones except the head zones (zone 1 and zone 2).

According to the measurement principles and calculation method mentioned above, the serial and parallel total thermal insulation and basic thermal insulation of one new and one old mining ensemble (including coats, trousers and boots) were obtained as shown in Table 1. It is seen that the thermal insulation of the mining uniform in China is bigger than working ensemble in normal workplaces (including shirts, trousers and shoes), since the mining uniform is made of pure cotton and the boots are made of pure leather for anti-static purpose and personal safety protection. The total thermal insulation on the mining ensemble calculated in serial way is a little bigger than that in parallel way, which is similar to 
previous studies $[15,17]$. Also, from Table 1 , it is found that the thermal insulation of the old mining ensemble worn for one year changes slightly from the new one. The local thermal insulations of the new and old mining ensembles are illustrated in Figure. 5. It is observed that there are notable differences of local thermal insulation among different body zones. The local thermal insulations of torso zones are lower, and the thermal insulation of the gluteal region is larger than those of other zones. Thermal insulations of shoulders, breast, abdomen, thigh regions are larger than those of extremities. Since upper arms are close to torso and legs approach closely, there are clothing overlapping at these area, and therefore thermal insulations of these area is larger. For coat and trousers overlap a lot at the gluteal region, the thermal insulation of gluteal zone is the highest. Thermal insulations at breast and abdomen zones are comparatively higher, because enclosed air layer at breast and abdomen region is thicker than that of other regions. In order to improve the thermal comfort of mining uniform, clothing parts of shoulders, breast, abdomen and thighs as well as the hidden clothing parts like the inner thighs could be made of thin fabrics or the fabrics of good air permeability.

Table 1. Serial and parallel total thermal insulation and basic thermal insulation

\begin{tabular}{ccccc}
\hline Mining & $\begin{array}{c}\text { Serial } \\
\text { total } \\
\text { thermal } \\
\text { ensemble } \\
\text { insulation } \\
\left(\mathrm{m}^{2} \cdot \mathrm{K} / \mathrm{W}\right)\end{array}$ & $\begin{array}{c}\text { Parallel } \\
\text { total } \\
\text { thermal } \\
\text { insulation } \\
\left(\mathrm{m}^{2} \cdot \mathrm{K} / \mathrm{W}\right)\end{array}$ & $\begin{array}{c}\text { Serial basic } \\
\text { thermal } \\
\text { insulation } \\
\left(\mathrm{m}^{2} \cdot \mathrm{K} / \mathrm{W}\right)\end{array}$ & $\begin{array}{c}\text { Parallel } \\
\text { basic } \\
\text { thermal } \\
\text { insulation } \\
\left(\mathrm{m}^{2} \cdot \mathrm{K} / \mathrm{W}\right)\end{array}$ \\
\hline New one & 0.202 & 0.192 & 0.119 & 0.108 \\
Old one & 0.209 & 0.198 & 0.123 & 0.111 \\
\hline
\end{tabular}

The testing temperature for the evaporative resistance of the mining ensemble was the same as measuring the thermal insulation, i.e. $25 \pm 0.3^{\circ} \mathrm{C}$ and the relative humidity was $55 \% \pm 3 \%$. Air velocity was less than $0.2 \mathrm{~m} / \mathrm{s}$. The skin surface $75 \sim 200 \mathrm{~mL} /\left(\mathrm{h} \cdot \mathrm{m}^{2}\right)$. Every experiment lasts 70 minutes. The temperature of "Newton" was set as $35^{\circ} \mathrm{C}$. The operation $75 \sim 200 \mathrm{~mL} /\left(\mathrm{h} \cdot \mathrm{m}^{2}\right)$. Every experiment lasts 70 minutes. The temperature of "Newton" was set as $35^{\circ} \mathrm{C}$. The operation mode of the manikin was sweating and the sweating rate is terminal temperature and the heat flux recorded at one-minute intervals after the heat output of each zone was steady for 30 minutes.

According to the measurement principles and calculation method mentioned above, the serial and parallel total evaporative resistance and basic thermal insulation of new and old mining ensemble were obtained as listed in Table 2. The total evaporative resistance and basic evaporative resistance calculated in serial way is slightly larger than that in parallel way, which resembles testing results of the thermal insulation. It is found that the evaporative resistance of the old mining ensemble worn for one year decreases about $15 \%$ compared with that of the new one. This is probably resulted by the indelible stains, which weaken the moisture transmission characteristic of the mining uniform. The local evaporative resistances of the new and old mining ensembles are illustrated in Figure. 6.

Table 2. Serial and parallel total evaporative resistance and basic evaporative resistance

\begin{tabular}{ccccc}
\hline $\begin{array}{c}\text { Mining } \\
\text { ensemble }\end{array}$ & $\begin{array}{c}\text { Serial total } \\
\text { evaporative } \\
\text { resistance } \\
\left(\mathrm{Pa} \cdot \mathrm{m}^{2} / \mathrm{W}\right)\end{array}$ & $\begin{array}{c}\text { Parallel } \\
\text { total } \\
\text { evaporative } \\
\text { resistance } \\
\left(\mathrm{Pa} \cdot \mathrm{m}^{2} / \mathrm{W}\right)\end{array}$ & $\begin{array}{c}\text { Serial basic } \\
\text { evaporative } \\
\text { resistance } \\
\left(\mathrm{Pa} \cdot \mathrm{m}^{2} / \mathrm{W}\right)\end{array}$ & $\begin{array}{c}\text { Parallel } \\
\text { basic } \\
\text { evaporative } \\
\text { resistance } \\
\left(\mathrm{Pa} \cdot \mathrm{m}^{2} / \mathrm{W}\right)\end{array}$ \\
\hline $\begin{array}{c}\text { New one } \\
\text { Old one }\end{array}$ & 50.75 & 43.73 & 27.82 & 23.13 \\
\hline
\end{tabular}

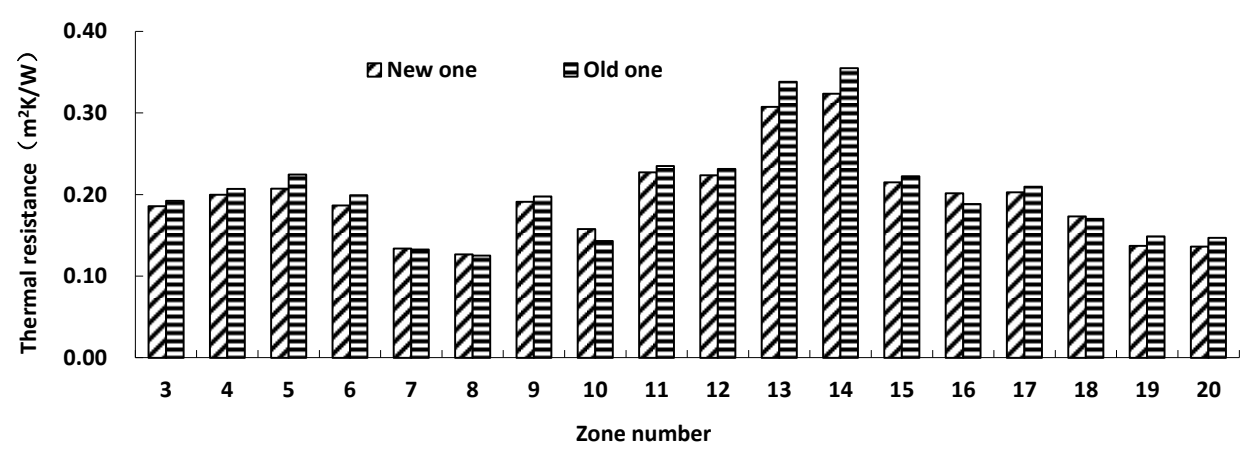

Figure 5. The local thermal insulation of each zone

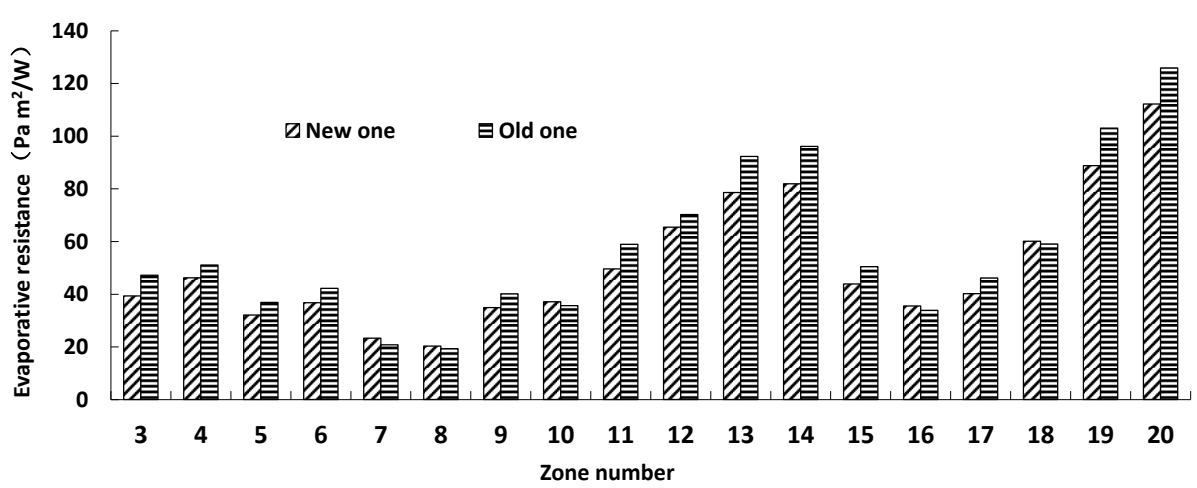

Figure 6. The local evaporative resistance of each zone 
It is seen that local evaporative resistances vary significantly among different regions in clothing resembles, while the change of local evaporative resistances is basically consistent with the thermal insulations of the mining ensemble. The evaporative resistance of foot zone is the highest among all of the body zones, and evaporative resistances of abdomen and gluteal zone are comparatively higher than other regions. The reason of these differences is the poor moisture permeability of boots and clothing overlapping at abdomen and gluteal region, which result in the inefficient heat-vapor exchange. In order to improve the efficient heat-vapor exchange of the abdomen zone, the gluteal zone and the foot zone, clothing parts with high evaporative resistances could be made of porous fabric, and the leather or rubber boots should be replaced by cloth shoes under the condition that the work regulation and operating condition meet safety requirements.

\subsection{Effect of testing temperature and relative humidity}

Secondly, considering the extreme thermal and humid conditions in the underground coal mines, we also investigated the effects of ambient temperature and relative humidity on the thermal insulation and evaporative resistance of the mining ensemble.

According to the measurement principles and procedures, the thermal insulation of the mining ensemble is firstly measured under a certain temperature at $25 \pm 0.3^{\circ} \mathrm{C}$ while with the relative humidity changing as $50 \%, 55 \%, 60 \%, 70 \%$, $80 \%, 90 \% \pm 3 \%$, and the air velocity was less than $0.2 \mathrm{~m} / \mathrm{s}$. The measured and calculated (in serial way) results are shown in Figure. 7. It is found that the total and basic thermal insulations of the mining ensemble have a significant decrease while the relative humidity exceeds $70 \%$, and the thermal insulation reduces almost $20 \%$ when the relative humidity increases from $50 \%$ up to $80 \%$ and then keeps at a constant level. This may be because the greater ambient relative humidity enlarges the moisture content of the mining ensemble, which enhances the heat transmission performance of the mining uniform. Moreover, the thermal insulation of the mining ensemble under different testing temperature was examined, and the measured and calculated results (local basic thermal insulation) under a certain humidity at $55 \% \pm 3 \%$ while with the testing temperature changing as $20 \pm 0.3^{\circ} \mathrm{C}$, $25 \pm 0.3^{\circ} \mathrm{C}, 30 \pm 0.3^{\circ} \mathrm{C}$ are illustrated in Fig. 8. It is observed that the local thermal insulation of the mining ensemble changes slightly under different thermal conditions, and thus the total evaporative resistance.
According to the measurement principles and procedures, the evaporative resistance of the mining ensemble is also measured under a certain temperature at $30 \pm 0.3^{\circ} \mathrm{C}$ while with the relative humidity changing as $55 \%, 70 \%, 80 \% \pm 3 \%$, and the air velocity was less than $0.2 \mathrm{~m} / \mathrm{s}$. The measured and calculated (in serial way) results are listed in Table 3 . It is found that the total evaporative resistance of the mining ensemble changes significantly at different relative humidity.

Table 3. Serial total evaporative resistance at different relative humidity

\begin{tabular}{cccc}
\hline Relative humidity & $\mathbf{5 5 \%}$ & $\mathbf{7 0 \%}$ & $\mathbf{8 0 \%}$ \\
\hline $\begin{array}{c}\text { Serial total evaporative resistance } \\
\left(\mathbf{3 0}^{\circ} \mathrm{C}\right) /\left(\mathrm{Pa} \cdot \mathrm{m}^{2} / \mathrm{W}\right)\end{array}$ & 60.10 & 44.88 & 41.72 \\
\hline
\end{tabular}

The evaporative resistance reduces almost $25 \%$ when the relative humidity increases from $55 \%$ to $70 \%$, and then decreases slightly. This is probably caused by the greater heat and moisture transmission performance of the mining uniform enhanced by the increase of the moisture content of the mining ensemble. Furthermore, the evaporative resistance of the mining ensemble under different testing temperature was measured, and the results (local basic evaporative resistance) under the certain humidity at $55 \% \pm 3 \%$ while with the testing temperature changing as $25 \pm 0.3^{\circ} \mathrm{C}$ and $30 \pm 0.3^{\circ} \mathrm{C}$ are presented in Figure. 9. It is found that the local evaporative resistance of the mining ensemble changes slightly under different thermal conditions, except some body zones (upper arm zone, feet zone and the gluteal region).

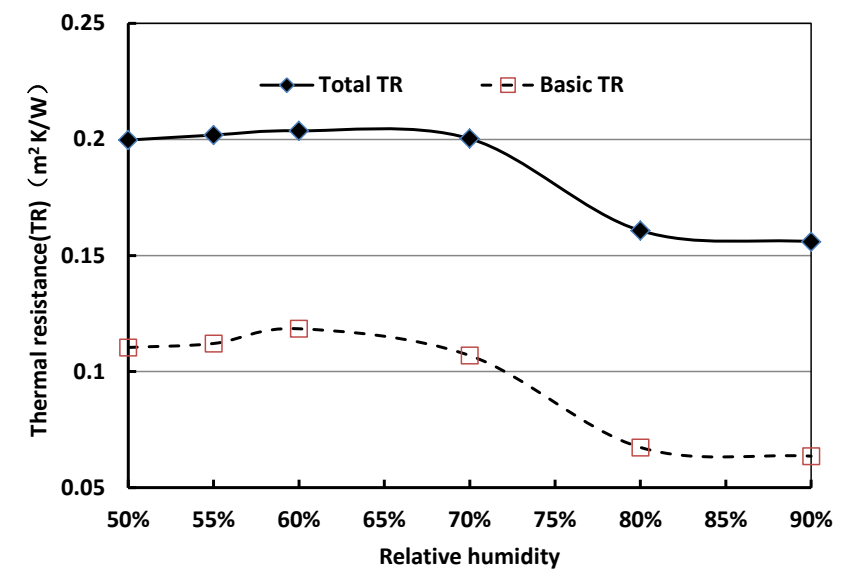

Figure 7. The thermal insulation changes with the relative humidity

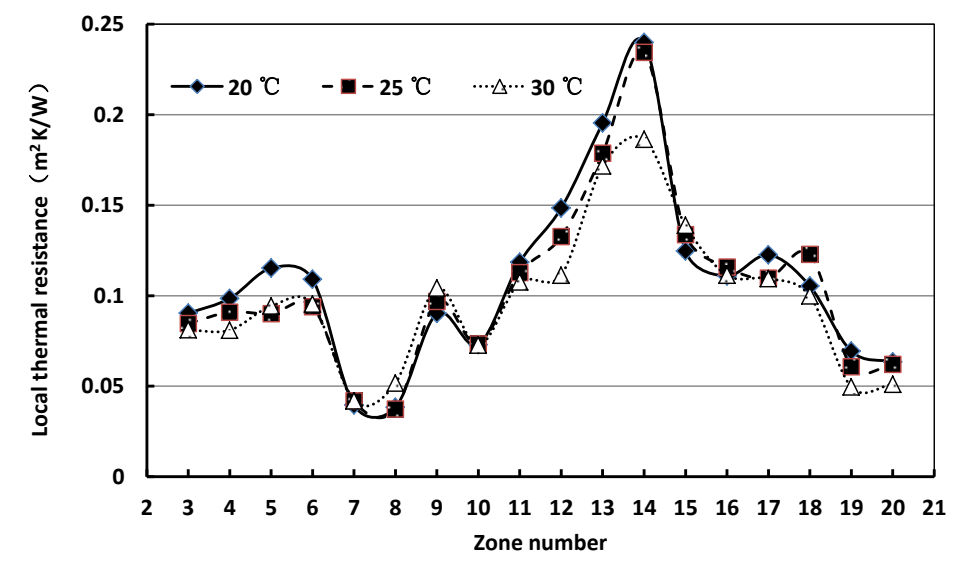

Figure 8. The local basic thermal insulation changes with the testing temperature 


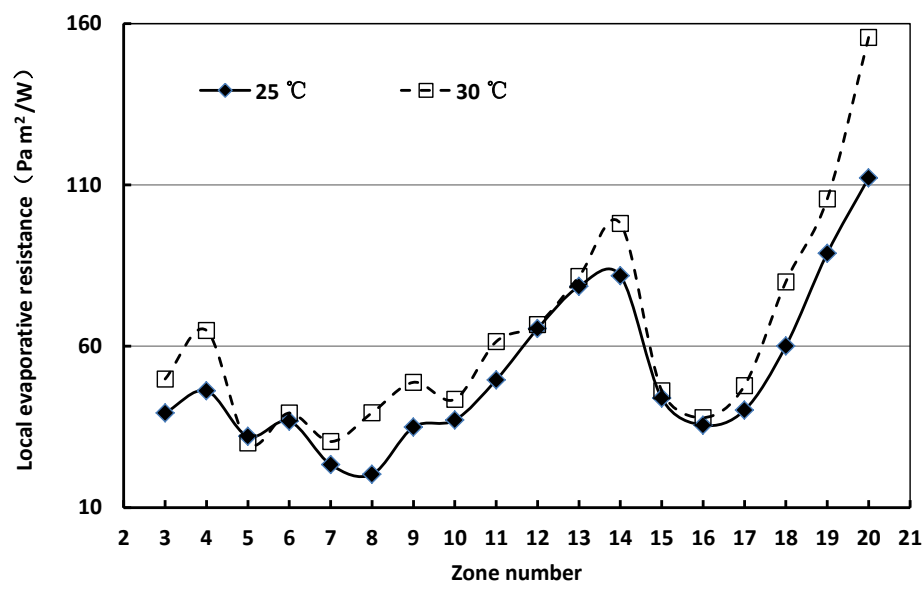

Figure 9. The local evaporative resistance changes with the testing temperature

\section{CONCLUSIONS}

In this study, the thermal insulation and the evaporative resistance of working ensembles for Chinese coal mines were measured and analyzed under standard thermal conditions and humid conditions, and furthermore examined when testing environmental conditions changes. It is found that:

a) The thermal insulation of the old mining ensemble worn for one year changes slightly from the new one, but the evaporative resistance decreases about $15 \%$.

b) There are notable differences of local thermal insulation among different body zones. The local thermal insulations of torso zones are comparatively lower, and the thermal insulation of gluteal zone is the highest. The thermal insulations of shoulders, breast, abdomen, thigh regions are larger than those of extremities.

c) The thermal insulation of the mining ensemble has a significant decrease while the relative humidity exceeds $70 \%$, and the thermal insulation reduces almost $20 \%$ when the relative humidity increases from $50 \%$ up to $80 \%$ and then keeps at a constant level. However, the thermal insulation changes slightly under different thermal conditions.

d) The evaporative resistance of the mining ensemble changes significantly at different relative humidity. The evaporative resistance reduces almost $25 \%$ when the relative humidity increases from $55 \%$ to $70 \%$, and then decreases slightly. Whereas, the evaporative resistance of the mining ensemble changes slightly under different thermal conditions, except for some body zones (upper arm zone, feet zone and the gluteal region).

\section{ACKNOWLEDGMENT}

This work was supported by National Key Research and Development Program of China (Grant No. 2016YFC0802801) and the National Natural Science Foundation of China (Grant No. 51574249).

\section{REFERENCES}

[1] Yang X.J., Han Q.Y., Pan J.W., Shi X.W., Hou D.G., Liu C. (2011). Progress of heat-hazard treatment in deep mines, Mining Science and Technology (China), Vol. 21, No. 2, pp. 295-299. DOI: $\underline{10.1016 / \text { j.mstc. } 2011.02 .015}$
[2] Qin Y.P., Kong S., Liu W., Wu J.S., Song H.T. (2015) Dimensionless analysis of the temperature field of surrounding rock in coalface with a finite volume method, International Journal of Heat and Technology, Vol. 33, No. 3, pp. 151-157. DOI: $10.18280 /$ ijht. 330323 .

[3] Shi B., Ma L., Dong W., Zhou F. (2015). Application of a novel liquid nitrogen control technique for heat stress and fire prevention in underground mines, Journal of Occupational and Environmental Hygiene, Vol. 12, No. 8, pp. 168-177. DOI: 10.1080/15459624.2015.1019074

[4] Wu J.S., Fu M., Tong X., Qin Y.P. (2017). Heat stress evaluation at the working face in hot coal mines using an improved thermophysiological model, International Journal of Heat and Technology, Vol. 35, No. 1, pp. 67-74. DOI: 10.18280/ijht.350109.

[5] Wacławik J. (2010). Numerical model of heat exchange between a worker body and the hot environment, Archives of Mining Sciences, Vol. 55, No. 3, pp. 3573-3588.

[6] Wang S., Ren T., Zhang T., Liang Y., Xu Z. (2012). Hot environment - Estimation of thermal comfort in deep underground mines, $12^{\text {th }}$ Coal Operators' Conference, University of Wollongong and the Australasian Institute of Mining and metallurgy, pp. 241-248.

[7] Huang W., Liu X., Zhang H. (2012). Study of underground thermal comfort based on thermal comfort equation, Mining Safety \& Environmental Protection, Vol. 39, pp.15-19. (In Chinese)

[8] Zhang J.Z., Chen Y.J. (2014). Discussion on control range of thermal environment in coal mine refuge chamber, Mining Safety and Environmental Protection, Vol. 41, No. 1, pp. 76-79. (In Chinese)

[9] Maurya T., Karena K., Vardhan H., Aruna M., Raj M.G. (2015). Effect of heat on underground mine workers, Procedia Earth and Planetary Science, Vol. 11, pp. 491-498. DOI: 10.1016/j.proeps.2015.06.049.

[10] Goldman R.F. (2006). Thermal manikins: Their origin and role, Thermal Manikins and Modelling, Hong Kong: The Hong Kong Polytechnic University, pp. 615.

[11] Zhao M.M., Li J., Wang Y.Y. (2013). Performance properties of cotton fabrics treated with phase change material microcapsules, Industria Textilă, Vol. 64, No. 1, pp. 13-19. 
[12] Wang F.M., Gao C.S., Kalev K., Ingvar H. (2011). Determination of clothing evaporative resistance on a Sweating thermal manikin in an isothermal condition: Heat loss method or mass loss method? Annals of Occupational Hygiene, 55(7):775-83.

[13] Fu M., Weng W., Yuan H. (2015). Combined effects of moisture and radiation on thermal performance of protective clothing: Experiments by a sweating manikin exposed to low level radiation, Vol. 27, No. 6, pp. 818-814. DOI: 10.1108/IJCST-05-2014-0064.

[14] Operator's Manual for "Newton", Measurement Technology Northwest, Seattle, WA, USA, 2011.

[15] Liu Y., Dai X. (2014). Measurement and calculation of clothing thermal resistance and evaporative resistance, China Personal Protective Equipment, No. 1, pp. 3236. (In Chinese)

[16] Virgilio A., Adelio M.O., Gaspar R., et al. (2008). Measurements of clothing insulation with a thermal manikin operating under the thermal comfort regulation mode: Comparative analysis of the calculation methods, Eur J Appl Physiol., Vol. 104, pp. 679-688. DOI: $10.1007 / \mathrm{s} 00421-008-0824-5$.

[17] Huang J.H. (2012). Theoretical analysis of three methods for calculating thermal insulation of clothing from thermal manikin, Ann. Occup. Hyg., Vol. 56, no.6, pp. 728-735. DOI: 10.1093/annhyg/mer118

[18] Havenith G., Nillsson H. (2004). Correction of clothing insulation for movement and wind effects, A meta-analysis, Eur. J. Appl. Physiol, Vol. 92, pp. 636640. DOI: $10.1007 / \mathrm{s} 00421-004-1113-6$.

[19] ISO 9920 (2007). Ergonomics of the thermal environment estimation of the thermal insulation and water vapour resistance of a clothing ensemble, International Standard (second ed.), International Organization for Standardization (ISO), Geneva, Switzerland. 